\title{
Contratos de fornecimento de cana-de-açúcar: as assimetrias de poder entre os agentes
} Suggar-cane supply agreement: the power asymmetry betweem agents Contratos de suministro de azúcar de caña: la asimetría de poder entre los agentes Les contrats des fournisseurs de cane à sucre: les inégalités du pouvoir entre les agents

\author{
Artêmio Ferreira Picanço Filho* \\ Joel Orlando Bevilaqua Marin**
}

Recebido em 28/5/2011; revisado e aprovado em 13/11/2011; aceito em 30/3/2012

\begin{abstract}
Resumo: O objetivo deste artigo é analisar os contratos firmados entre as agroindústrias canavieiras e agricultores fornecedores de cana para a obtenção de matéria-prima, a partir de um estudo de caso realizado em Goiás. Concluise que as agroindústrias detêm o poder de informações, gerando assimetrias nas relações sociais, o que obriga os fornecedores a aceitarem as imposições das agroindústrias canavieiras e permanecerem integrados a elas, por falta de melhores alternativas de inserção econômica.
\end{abstract}

Palavras-chave: Agroindústria canavieira. Cana-de-açúcar. Assimetrias de poder

Abstract: The aim of this work is to analyze the agreements dealt between the sugar-cane agribusiness and the sugar-cane suppliers for raw material supply based upon a case study in Goiás State, Brazil. The conclusion is that the sugar-cane agribusiness keeps the control on the information producing asymmetry in the social relationship forcing the raw material suppliers to accept its impositions keeping them linked to its interest due to absence of better economical options.

Key words: Sugar-cane agribusiness. Sugar-cane. Power asymmetry.

Résumé: L'objectif de cet article est d'analyser les contrats accordés entre les industries agroalimentaires de canne à sucre et les agriculteurs fournisseurs de cane pour l'obtention de la matière-première, à partir d'une étude de cas réalisée dans l'état de Goiás. La conclusion est que les industries agroalimentaires détiennent le pouvoir d'information, gérant les inégalités des relations sociales, ce qui oblige les fournisseurs à accepter les conditions des industries agroalimentaires de canna à sucre et à leur demeurer fidèles, à défaut de meilleures alternatives d'insertion économique.

Mots-clés: Agroalimentaires de canne à sucre. Canne à sucre. Inégalités du pouvoir.

Resumen: El objetivo de este trabajo es revisar los contratos entre los agricultores y la agroindustria de caña de azúcar proveedores de caña para obtener materia prima de un estudio de caso en Goiás concluir que las agroindustrias tienen el poder de la información, la generación de las asimetrías en las relaciones sociales, que exige a los proveedores a aceptar las imposiciones de la industria de la caña de azúcar integrarse y permanecer en ellos, a falta de mejores alternativas para la inclusión económica.

Palabras clave: Agroindustria de caña de azúcar. Caña de azúcar. Las asimetrías de poder.

\section{Introdução}

O grande desafio das agroindústrias canavieiras está relacionado com o fornecimento da matéria-prima, dada a elevada especificidade dos processos de produção e transformação da cana-de-açúcar. A estrutura de governança no setor sucroalcooleiro oscila entre os contratos de fornecimento de canade-açúcar, estabelecidos com os fornecedores para obtenção de matéria-prima, e os contratos de arrendamento de terra, firmados com os proprietários de imóveis, que permitem que as agroindústrias canavieiras operem com canaviais próprios. Os contratos agrários fir- mados entre agroindústrias sucroalcooleiras e fornecedores de cana-de-açúcar são permeados por diversos interesses, que expressam consensos e conflitos.

Este trabalho tem por objetivo analisar as relações contratuais de integração no setor canavieiro, sob a perspectiva dos fornecedores de cana, avaliando em que medida esses agentes aceitam ou se contrapõem às regras contratuais impostas pelas agroindústrias. Com base em depoimentos orais dos agricultores integrados e de seus representantes sindicais rurais, procurou-se compreender os consensos e conflitos que emergem das formas contratuais firmadas entre as

\footnotetext{
* Mestre em Agronegócios pela Universidade Federal de Goiás (UFG). Contador. Professor substituto da Universidade Federal de Goiás e professor da Associação de Educação e Cultura de Goiás (AECG). E-mail: arte1000picanco@yahoo.com.br

** Doutor em Sociologia. Professor da Universidade Federal de Santa Maria (UFSM).

E-mail: bevilaquamamarin@gmail.com
} 
agroindústrias canavieiras e fornecedores de cana para obtenção de matéria-prima. $\mathrm{O}$ estudo de caso foi realizado no município de Quirinópolis, situado no Sudoeste Goiano. A escolha foi dirigida, pelo fato de as usinas localizadas nesse município adquirirem de fornecedores mais de $50 \%$ da cana-de-açúcar, o que propicia melhores condições para analisar a modalidades de contratos agrários referentes à compra de matéria-prima.

Realizou-se análise dos contratos agrários firmados entre agroindústrias canavieiras e fornecedores de cana-de-açúcar. Além da pesquisa desses documentos, desenvolveu-se um estudo de caso no município de Quirinópolis, envolvendo dezesseis fornecedores de cana-de-açúcar que mantêm relações contratuais no sistema de integração para suprir a agroindústria de matéria-prima. Também foram realizadas entrevistas junto a diversos órgãos ou entidades relacionadas com o setor sucroalcooleiro, tais como a Associação dos Fornecedores de Cana de Goiás (APROCANA), a Federação da Agricultura do Estado de Goiás (FAEG), Sindicatos Rurais de Quirinópolis e Sindicato da Indústria de Fabricação de Álcool do Estado de Goiás (SIFAEG).

$\mathrm{O}$ artigo está dividido em três seções. A primeira analisa o caso das agroindústrias canavieiras, com ênfase no processo histórico desde a implantação, desenvolvimento e importância no âmbito do município e região onde se instalaram. A segunda seção trata da relevância dos contratos de fornecimento de cana-de-açúcar, como instrumento de integração entre as agroindústrias e os produtores rurais para fornecimento de matéria-prima, demonstrando que o poder monopolístico, associado às informações assimétricas, proporciona vantagens às agroindústrias, em detrimento dos produtores rurais, e acarreta conflitos que emergem dessas relações contratuais. A terceira seção relata os diversos tipos de assimetrias de poder existentes entre os produtores rurais, o que proporciona diferenças de vantagens entre eles nas negociações estabelecidas com as agroindústrias.

\section{Lavoura canavieira em Quirinópolis}

A atividade canavieira tem grande importância no desenvolvimento socioeconômico do município goiano de Quirinópolis, com destaque na produção de açúcar, álcool e cogeração de energia. Atualmente, segundo o Sindicato da Indústria de Fabricação de Álcool do Estado de Goiás (SIFAEG), o município representa um dos maiores produtores de cana-de-açúcar do Estado de Goiás. As informações orais, obtidas dos representantes dos Sindicatos Rurais, fornecedores de cana e associações comerciais, evidenciam as vantagens e benefícios proporcionados pelo setor sucroalcooleiro no município, com destaque para a geração de empregos, aumento das vendas no comércio, crescimento no setor de prestação de serviços, entre outros.

O município de Quirinópolis não tinha tradição na cultura de cana-de-açúcar até o ano de 2004 nem possuía agroindústria canavieira em seu território. Os estímulos das políticas públicas federais e dos incentivos fiscais do governo estadual, instituídos pelo Programa Nacional de Agroenergia, foram determinantes para que grupos empresariais do Estado de São Paulo instalassem usinas de beneficiamento de cana-de-açúcar no município.

Após a instalação das agroindústrias canavieiras no município de Quirinópolis, a produção de cana-de-açúcar teve um expressivo crescimento. No ano de 2006, a produção de cana-de-açúcar foi de $600 \mathrm{mil}$ toneladas, experimentando um significativo crescimento nos anos seguintes: $765 \mathrm{mil} \mathrm{em}$ 2007 e 2.400 mil em 2008. No ano de 2009, atingiu o patamar de 3.072 mil toneladas de cana-de-açúcar colhida, correspondente a um crescimento de $412 \%$ no período 2006 a 2009 (Figura 1). Com isso, conforme informações do Sifaeg, o município de Quirinópolis se tornou o maior produtor de cana-de-açúcar do Estado de Goiás. 


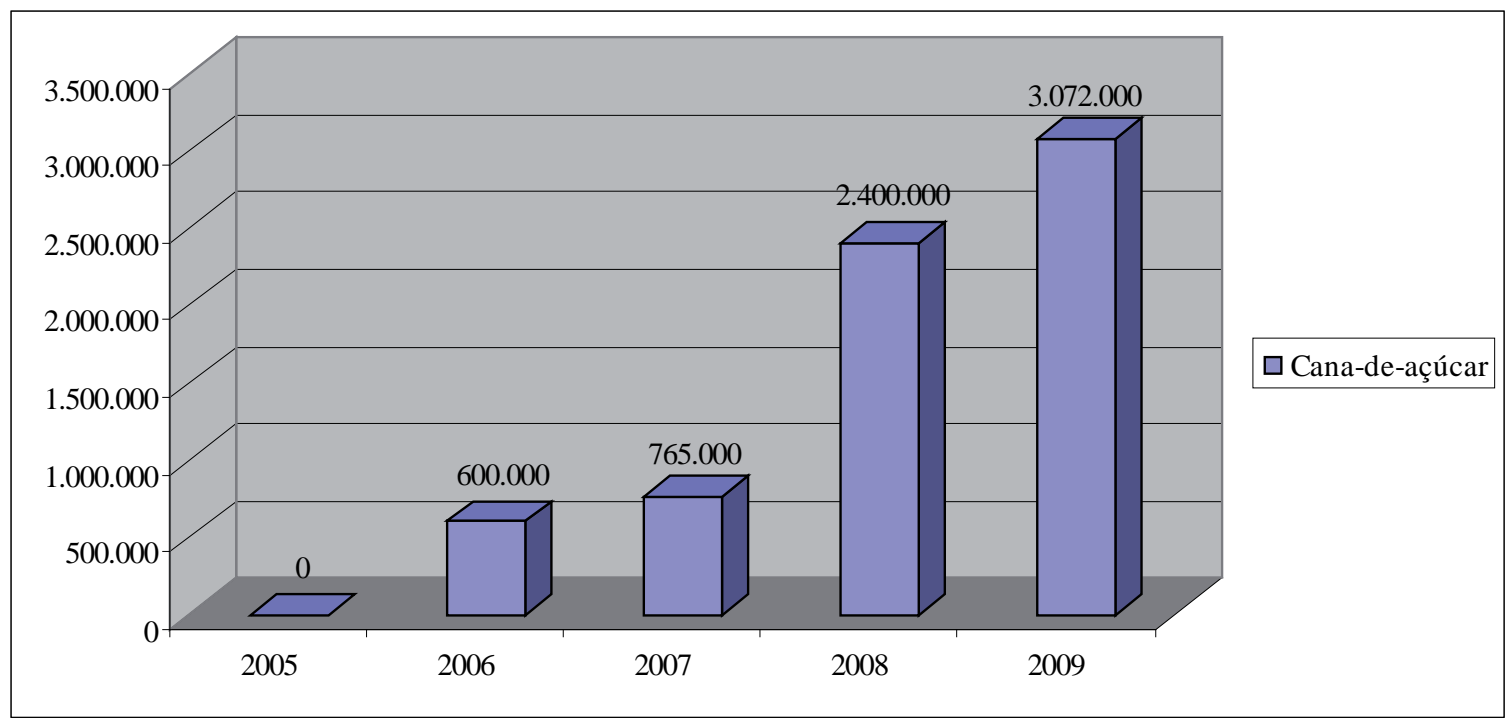

Figura 1 - Evolução da produção de cana-de-açúcar em toneladas, no município de Quirinópolis no período de 2005 a 2009.

Fonte: Instituto Brasileiro de Geografia e Estatística (IBGE). Dados obtidos na SEPLAN/SEPIN (2010).

Segundo representantes da Federação da Agricultura do Estado de Goiás (FAEG), o município de Quirinópolis também se destaca em Goiás pelo expressivo número de agricultores fornecedores de cana-de-açúcar. Acredita-se que esse fato contribui sensivelmente para o aumento do produto interno bruto (PIB) municipal, em face da maior circulação da receita oriunda da cadeia produtiva da cana, evitando a concentração de rendas por parte das usinas.

Quando ocorreu a instalação das agroindústrias no município, a atividade agropecuária de bovinocultura de corte, as culturas de soja, milho, entre outras, atravessavam séria crise econômica e financeira. Os produtores encontravam-se endividados e com dificuldades para continuar na atividade. Assim, procuravam outras fontes de renda, a fim de solucionar os problemas vivenciados nos últimos anos. Por conseguinte, as agroindústrias não tiveram dificuldades em atrair produtores dispostos a mudar de atividade em benefício da produção canavieira e se tornarem fornecedores.

Por ocasião da pesquisa em 2009, a agroindústria canavieira encontrava-se no período de corte da terceira safra de cana. Constatou-se que as relações contratuais entre os agentes aparentavam uma relativa normalidade, embora houvesse alguns conflitos quanto aos valores pagos pela cana.
Todavia os dissensos não foram suficientes para comprometer o relacionamento das partes envolvidas, pois os produtores demonstravam confiança no desenvolvimento da atividade no município. Entendendo-se como "parceiros" das empresas, os produtores viram as pequenas tensões quanto aos preços como resultado da crise mundial que afetou toda a atividade econômica.

Nas agroindústrias situadas no município de Quirinópolis, mais da metade da matéria-prima é originada de aquisição de fornecedores de cana-de-açúcar. Em virtude das peculiaridades da atividade canavieira, é necessária a adoção de medidas administrativas coordenadas e adequadas para evitar prejuízos para as agroindústrias canavieiras. $\mathrm{Na}$ expectativa de solucionar esses entraves, a tendência desse suprimento tem sido a integração, representada pelos contratos de fornecimento de matéria-prima firmados entre as agroindústrias e produtores rurais. A elaboração desses contratos é complexa, se consideradas as incertezas e as imprevisibilidades de contingências futuras, que aumentam a possibilidade de celebrar contratos incompletos suscetíveis de ocasionar eventuais conflitos entre as partes.

As especificidades da cultura canavieira podem ser compreendidas como uma teoria econômica de contratos. Por isso, devem ser analisadas como transações, que são relações 
contratuais entre as partes cujos direitos e obrigações a serem cumpridas no futuro, com possibilidades de ajuste ao longo do tempo. Nas relações sociais contratuais, pode-se verificar o comportamento oportunista, em que as agroindústrias canavieiras tendem a fugir das responsabilidades e buscam obter o máximo de benefícios em face das informações assimétricas que detêm, proporcionando a inclusão de cláusulas contratuais favoráveis a seus interesses (VIAN, 2003).

Os contratos de fornecimento de cana-de-açúcar podem ser tanto em forma escrita como verbal e celebrados por prazo determinado e indeterminado. Os contratos celebrados pelas agroindústrias canavieiras de Quirinópolis com os fornecedores de cana-de-açúcar são todos formalizados e com prazo mínimo, cumprindo em seus quesitos as disposições estabelecidas no Estatuto da Terra.

\section{Contratos para aquisição de matéria-prima}

O fornecedor de cana é um agente social que se constituiu dos aparatos jurídicos, promulgados com vistas a regulamentar as relações sociais no espaço agrário brasileiro. $\mathrm{O}$ fornecedor de cana, em termos legais, surgiu no início da década de 1940, com a institucionalização do Estatuto da Lavoura Canavieira, por meio do Decreto-Lei n. 3.855 de 21 de novembro de 1941. Esse documento jurídico não apenas lançou as bases conceituais para definir o que deve ser entendido por fornecedor de cana, mas também tratou de estabelecer, com certa precisão, as relações sociais e jurídicas que tal agente pode ou não estabelecer socialmente. No exercício do seu domínio burocrático, coube ao Estado uniformizar as concepções para o entendimento desses agentes sociais e delimitar suas formas aceitáveis de vinculação contratual perante o próprio Estado e demais agentes sociais. $O$ poder burocrático estatal passou a regulamentar as relações sociais que devem estar pautadas em relações contratuais e dotadas de impessoalidade.

Historicamente, as relações sociais no setor canavieiro, envolvendo usina e fornecedores de cana, eram marcadas pela existência de inúmeros conflitos e descontentamentos. Cumprindo seu papel de instituidor de normas e leis racionais, no que diz respeito à necessidade de manter a normalidade e solucionar os diversos problemas de ordem econômica e social, o Estado, em 1933, criou o Instituto do Açúcar e do Álcool (IAA), com a função de legislar e executar as políticas públicas voltadas para o setor canavieiro. Posteriormente, em 1941, foi elaborado o Estatuto da Lavoura Canavieira (ELC), sendo seu objetivo principal reconhecer e estabelecer os direitos e deveres dos fornecedores de cana-de-açúcar. Conforme o artigo 39, se a usina se recusar a receber a cana do fornecedor, ficará obrigada a ressarcir pelo dano causado a este. No entanto, pelo artigo 43, o fornecedor que deixar de entregar, durante uma safra, parte ou a totalidade de sua quota de fornecimento à usina a que esteja vinculado, terá o seu limite reduzido à quantidade de que haja efetivamente entregue. Dessa forma, os fornecedores vendem sua produção de cana para as usinas que têm o compromisso de adquirir essa produção.

Atualmente, as normas gerais dos contratos de sociedade passaram a ser regulamentadas pelo Código Civil de 2002, em que as relações contratuais do tipo fornecimento de matéria-prima se enquadram como "contrato de compra e venda", previsto do Código Civil. O artigo 481 reza:

[...] pelo contrato de compra e venda, um dos contratantes se obriga a transferir o domínio de certa coisa, e o outro, a pagar-lhe certo preço em dinheiro.

\section{O artigo 483 complementa:}

[...] a compra e venda pode ter por objeto coisa atual ou futura. Neste caso, ficará sem efeito o contrato se esta não vier a existir, salvo se a intenção das partes era de concluir contrato aleatório.

Com o início da atividade canavieira em Quirinópolis e a grande participação dos fornecedores de cana-de-açúcar na produção de matéria-prima às agroindústrias canavieiras, em outubro de 2006 foi fundada a Associação dos Fornecedores de Cana Goiás - Marcelo Rezende Calil (APROCANA). Esta mantém convênio com a Organização dos Plantadores de Cana da Região Centro-Sul do Brasil (ORPLANA) e a Federação dos Plantadores de Cana do Brasil (FEPLANA). A APROCANA presta assistência a seus associados, sobretudo nas áreas técnicas e agronômicas com pertinência às etapas de formação e manutenção dos canaviais. 
Os fornecedores reconhecem o importante serviço prestado pela associação por ocasião da colheita. Nesse período, a APROCANA mantém técnicos durante 24 horas junto à usina, para aferir a balança, acompanhar as entregas de cana, bem como retirar a amostra de cana para medição do teor de Açúcar Total Recuperável (ATR). Quanto à assessoria jurídica, porém,esta deixa a desejar, pois não dispõe de um quadro técnico qualificado para discutir em condições de igualdade com as agroindústrias todas as cláusulas contratuais que possam coibir a formalização de contratos incompletos. Essas diferenças de informações para discutir as cláusulas contratuais muitas vezes podem trazer prejuízos financeiros para os fornecedores.

A integração consiste em uma forma de articulação vertical entre agroindústrias e produtores agropecuários, em que o processo de produção é organizado industrialmente, com aplicação de tecnologia e capital. Os produtores integrados são aqueles que recebem insumos ou orientações técnicas de uma agroindústria, com o objetivo de produção de matéria-prima e, em contrapartida, ficam obrigados a vender a produção para a referida empresa (PAULILO, 1990).

Para atender parte da matéria-prima necessária ao funcionamento das unidades produtoras, as agroindústrias canavieiras celebram contratos de fornecimento de canade--açúcar com os produtores rurais interessados em produzir a cultura. Considerada uma necessidade de ambas as partes, essa transação é permeada por conflitos e embates. Como destacam Waack e Neves (1998, p. 14),

[...] a transação de venda de cana entre produtores e usinas é um dos pontos mais importantes e conflituosos do Sistema Agroindustrial (SAG) da cana-de-açúcar.

Nesse contexto, cabe referir o que Fiani (2002, p. 270) denomina assimetrias de informação. Trata-se das diferenças nas informações que as partes envolvidas em uma transação possuem, particularmente quando essa diferença afeta o resultado final da transação". No caso da agroindústria canavieira, as assimetrias de informações tornam-se importantes estratégias de gestão nos contratos de compra de matéria-prima. Assim, observou-se que a maioria dos conflitos é decorrente do pouco conhecimento dos fornecedores de cana. Mesmo representados por suas entidades de classe, eles não dispõem de todas as informações necessárias efundamentais para discutir em condições de igualdade com as agroindústrias canavieiras. Estas, por sua vez, dispõem de um aparato de informações sobre as leis, normas, financeiras, econômicas, tecnológicas, mercadológicas, sociais, dentre outras, que facilitam a definição das condições e cláusulas contratuais envolvidas nas transações.

Os agentes sociais do setor canavieiro apresentam diferenças de poder econômico, grau de instrução, participação política, o que implica diferentes tipos de comportamentos, em razão das condicionantes estabelecidas nas relações sociais contratuais. Com isso, nas negociações, os agricultores acabam aceitando as condições impostas pelas agroindústrias, com prováveis consequências desfavoráveis no futuro. O domínio de informações torna-se o principal fator de poder que as empresas utilizam para manter a coordenação e decisão da cadeia produtiva da cana-de-açúcar, de maneira favorável aos seus interesses.

Para efetivar as integrações e as relações sociais com esses produtores, foram realizadas negociações entre as partes envolvidas, através de contratos de fornecimento de matéria-prima, nos quais constam os direitos e deveres de cada parte nessa transação. Os produtores de matéria-prima para agroindústria são comumente denominados parceiros integrados.

Mesmo transferindo para o agricultor o compromisso de produção da matéria-prima, a indústria não transfere a autonomia com relação à maneira de produzir, ficando o integrado obrigado a uma padronização das condições técnicas, para serem atingidos o padrão da racionalidade e o nível de acumulação que a empresa se propõe, visando obter o controle de todo o processo produtivo (PAULILO, 1990).

Contudo os fornecedores de cana-de-açúcar, embora assumindo todos os riscos inerentes à atividade, estão sujeitos a observarem determinadas normas oriundas das agroindústrias, como orientação a respeito do plantio da cana, tratos culturais e cronograma para a colheita. Ademais, as agroindústrias são detentoras dos recursos tecnológicos, principalmente máquinas e equipamentos 
necessários para colheita, carregamento e transporte, que são bastante dispendiosos. Assim, elas mantêm controle e ingerência junto aos produtores, com vistas a obter matéria-prima com qualidade e quantidade necessária para seu processo produtivo, no momento oportuno.

Para a máxima eficiência no alcance dos objetivos, as agroindústrias canavieiras normatizam os procedimentos adequados ao funcionamento das unidades de produção. Um desses procedimentos se restringe à transação para obtenção de matéria-prima. Para isso, torna-se necessária a formalização de contratos com os fornecedores de cana, com base nas regras, normas regulamentadoras emitidas pelo Estado e demais órgãos relacionados à atividade canavieira, além de outros procedimentos operacionais.

Para viabilizar a instalação das Usinas em Quirinópolis, GO, os dirigentes procuraram produtores rurais interessados em se integrar à indústria para produção e fornecimento de cana-de-açúcar. Como incentivo, as usinas se propuseram a fornecer gratuitamente as mudas, bem como prestar orientação técnica e agronômica sobre a nova cultura, como pode ser observado nas declarações de um fornecedor que cultiva 72 hectares de cana-de-açúcar: "A usina forneceu as mudas para a formação, o que representa um valor alto na formação do canavial, em torno de $20 \% "$.

Também ofereceram subsídios aos custos de transporte da matéria-prima, para distâncias superiores a 25 quilômetros da unidade industrial, de conformidade com as informações de um fornecedor de cana que trabalha numa área de 80 hectares: "Aqui a usina dá subsídio do frete, devido à distância. Minha fazenda está a $43 \mathrm{~km}$, eu pago o frete com base em $25 \mathrm{~km}$ ".

Ademais, se comprometeram a disponibilizar recursos tecnológicos e logísticos para implantação de canaviais para acerto nas safras futuras ou quando os produtores disponibilizassem recursos. O depoimento a seguir, de um fornecedor de 650 hectares de cana-de-açúcar, é elucidativo:

A formação do canavial foi toda mecanizada com máquinas da usina. Ela mesma contratou os trabalhadores para plantar, deu assistência técnica e tudo.
Tendo em vista o somatório de vantagens e benefícios, a usina não teve dificuldades de encontrar produtores dispostos a fornecer cana-de-açúcar, com os quais celebrou contratos para fornecimento de matéria-prima. Os incentivos e os propósitos da usina foram determinantes para o desenvolvimento da atividade canavieira em Quirinópolis, principalmente no que se refere aos incentivos para os fornecedores de cana, que foram beneficiados com recursos financeiros oferecidos pela usina para pagamento por ocasião das respectivas colheitas.

Conforme cláusulas contratuais, o preço do fornecimento da matéria-prima é o valor líquido apurado ao final do ano-safra, a partir da metodologia estabelecida pelo CONSECANA/SP. Para implementação desse método, as agroindústrias concedem um adiantamento de $80 \%$ na primeira quinzena do mês subsequente ao recebimento da cana do fornecedor, calculado com base na média de quilograma de ATR, divulgado pelo CONSECANA/SP. Os 20\% remanescentes serão pagos até o final do ano-safra de canade-açúcar, que ocorre no mês de abril, com base na quantidade de ATR entregue pelo parceiro fornecedor, durante a safra.

Constatou-se que, na safra 2008-2009, o pagamento do valor residual não ocorreu na época aprazada, o que provocou descontentamentos e prejuízos financeiros aos produtores, pois estes assumiram compromissos com empresas fornecedoras de insumos e terceiros para realizar os serviços de tratos culturais e adubação dos canaviais. A usina já normalizou o pagamento do valor remanescente aos fornecedores de cana, entretanto o não recebimento desses direitos acarretou atrasos nos pagamentos dos compromissos assumidos pelos fornecedores, com altas taxas de juros cobrados pelos credores. Embora tenham tentado junto à agroindústria os ressarcimentos dos juros pagos, não obtiveram êxito.

Nota-se que há, portanto, uma aceitação racional da atuação das agroindústrias sucroalcooleiras com relação aos negócios concretizados. Esse descontentamento não significa necessariamente a intenção de mudar de atividade, haja vista a ausência de alternativa mais atraente, além do fato de que não estão dispostos a assumir elevados investimentos financeiros e arcar com os riscos e 
desconfortos que qualquer tipo de mudança poderia demandar.

É notório que as agroindústrias canavieiras instaladas no Brasil dispõem da força de poder econômico, político e social. Mais especificamente, elas detêm poderes de barganha, em decorrência das assimetrias de informações, o que lhes possibilita articular um conjunto diversificado de recursos de poder e domínio. De acordo com Paulillo e Almeida (2009, p. 4), os poderes das agroindústrias canavieiras se expressam nos aspectos "constitucionais, políticos, financeiros, tecnológicos, organizacionais e jurídicos".

Nesse sentido, as agroindústrias instaladas em território goiano exercem o poder do monopólio sobre os produtores rurais que fornecem cana, mediante a utilização de métodos racionais que dificultam ações sociais de enfrentamento. Isso ocorre em virtude do receio de terem de assumir maiores prejuízos ou mesmo de perder os negócios estabelecidos com essas empresas. Dessa forma, os produtores preferem aceitar as condições impostas na relação de integração com a agroindústria, na esperança de obterem melhores resultados financeiros e econômicos no futuro.

Com o atraso no pagamento de parte do fornecimento de cana-de-açúcar - o que não aconteceu com o arrendamento -, além dos riscos de perda da lavoura canavieira, da falta de recursos para financiamento de novos de canaviais, agentes de representação vinculados à FAEG, Sindicato Rural, APROCANA e também alguns fornecedores de cana estão receosos de que, no vencimento dos contratos, parte dos atuais fornecedores deixe de produzir e passe a arrendar suas terras. Aqueles agentes de representação dos agricultores avaliam que a transferência de toda a produção da cana para a agroindústria não seria boa para o desenvolvimento econômico do município, posto que implicaria a concentração da renda e maior poder agroindustrial no município de Quirinópolis.

Em que pese ao fato de os contratos estipularem que o pagamento pelo fornecimento de cana-de-açúcar será calculado com pela média do ATR individual do fornecedor, na safra 2008-2009 a usina utilizou o valor para pagamento da produção com base na média do ATR da usina. Assim, os fornecedores que realizaram os devidos tratos culturais, com gastos elevados em adubação e cobertura dos canaviais, e atingiram uma média de ATR superior à da usina, tiveram suas receitas reduzidas, o que gerou conflitos.

Esse problema parece ser comum tanto aos grandes quanto aos pequenos fornecedores. Os depoimentos dos fornecedores a seguir, que cultivam áreas de 72 e 2.000 hectares, respectivamente, concordam que não há cumprimento de cláusula contratual pela agroindústria canavieira:

Nós precisamos trabalhar as ATRs individuais. A usina está trabalhando com uma ATR média que prejudica quem zela bem da cana.

Eu tive um prejuízo grande, mostrei isso para a usina. Ela não concordou, mesmo estando no contrato. A minha produção individual deu $167 \mathrm{~kg}$ de ATR; a usina me pagou pela média dela, que foi 142 . Veja a diferença. Enquanto uns perdem outros ganham.

Outra transação contratual que tem causado dissensos envolvendo fornecedores e usinas diz respeito à colheita da cana-de-açúcar - corte, carregamento e transporte (CCT) -, por envolver vários fatores. Um deles é o custo do CCT, que oscila de $35 \%$ a $60 \%$ da receita bruta da produção, uma vez que está diretamente relacionado com a distância e média de ATR do produtor. Outro fator tem a ver com a época de colheita, que é determinada pela agroindústria e influi decisivamente na produtividade e na média de quilograma de ATR da cana-de-açúcar. Além disso, os recursos tecnológicos para realizar esses serviços têm custos elevadíssimos, inviabilizando a qualquer fornecedor fazer suas aquisições, se forem comparados os custos com os benefícios.

A agroindústria canavieira monopoliza essa etapa da produção, uma vez que detém os recursos logísticos, financeiros, científicos e tecnológicos, materializados nos equipamentos necessários para os serviços de colheita. Detendo ainda os conhecimentos econômicos, mercadológicos, jurídicos e contábeis, a usina elabora, à revelia dos produtores, as respectivas planilhas de preço que servirão de base para cobrança pela execução desses serviços. Aos fornecedores de cana resta mesmo acatar a decisão.

$\mathrm{Na}$ atividade canavieira goiana, evidencia-se certa aceitação por parte dos produtores 
rurais. Isso porque a maioria dos entrevistados é convicta de que as agroindústrias obtêm vantagens com essa forma de negociação e que nem sempre é compensada satisfatoriamente. Os fornecedores até expressam discordâncias com os procedimentos remuneratórios da cana, mas sentem-se um tanto impotentes para enfrentar o domínio exercido sobre o controle e critérios da ATR. Entretanto, no balanço das desvantagens que os produtores encontram com as demais atividades rurais, eles não percebem alternativas capazes de lhes satisfazer plenamente.

Diante do domínio do monopólio econômico da agroindústria, podem-se compreender as ações sociais de impotência dos produtores, que resulta na aceitação das condições impostas nos contratos, mesmo com prejuízos financeiros decorrentes dos atrasos nos pagamentos do fornecimento da produção de cana-de-açúcar. É evidente que a pouca informação inibe ações sociais de negociação dos fornecedores, para exigir seus direitos em face da assimetria de poder que a agroindústria canavieira detém. Assim, acatam os procedimentos adotados pelas empresas, embora insatisfeitos.

Segundo Fiani (2002), as assimetrias de informações proporcionam poder para a empresa, em detrimento dos fornecedores de cana-de-açúcar. Trata-se de desigualdade de informações que poderia ser contornada se os fornecedores de cana-de-açúcar conhecessem, além das normas gerais dos contratos, outras informações detidas pelas agroindústrias. Dessa maneira, vários fatores são determinantes para que os fornecedores deixem de exigir o cumprimento das cláusulas contratuais pela via judicial e prefiram uma "negociação amigável". Mesmo cônscios de que estão sendo prejudicados, justificam-se por se considerarem o lado mais fraco na relação. Eles precisam manter as relações contratuais com as agroindústrias e, temerosos das consequências que podem advir em caso de uma briga judicial, preferem "um pequeno acordo a uma grande demanda".

Primeiro, os fornecedores de cana dispõem de poucas informações e de limitada assistência jurídica das entidades representativas capazes de torná-los em condições de discutir em igualdade, perante o recurso de poder das agroindústrias canavieiras. Além disso, a contratação de um especialista na área jurídica, somada aos elevados custos de uma ação judicial, afeta sensivelmente o baixo orçamento dos produtores. Isso sem contar a morosidade da justiça brasileira que, no caso de uma ação judicial, prejudicaria a atividade rural.

Segundo, uma vez ajuizada uma ação contra a agroindústria, o fornecedor dificilmente terá condições de continuar com a atividade, pois a usina não receberá produção de cana-de-açúcar. Tendo em vista o mercado monopolístico específico da produção de cana-de-açúcar, o produtor não conseguirá vender a matéria-prima, por falta de mercado alternativo, pois a uma distância maior que $50 \mathrm{~km}$ da usina, as despesas com o transporte e os custos de produção seriam onerosos, podendo ser superiores às receitas. Ademais, dada a cláusula de fidelidade existente no contrato, outra agroindústria canavieira, mesmo próxima do imóvel, dificilmente adquiriria a cana-de-açúcar do fornecedor. Isso em função da observância da preservação da ética e das estratégias negociais.

Por fim, a cana-de-açúcar é uma cultura permanente. Uma vez formada, proporciona renda por vários anos, de forma que os elevados custos de formação dos canaviais serão diferidos durante o período de produção, proporcionando lucro aos fornecedores. Caso entrem em litígio com a usina, além de assumir grandes prejuízos decorrentes da produção não colhida no período de vida útil da lavoura canavieira, os produtores não terão condições de iniciar uma nova atividade, em função da escassez de recursos econômicos e financeiros.

Uma estratégia diferencial adotada pela Usina que os fornecedores reconhecem ser favorável aos seus interesses relaciona-se com a cana não colhida. Pela cláusula contratual, a agroindústria tem o compromisso de comprar toda a produção do fornecedor, entretanto nem todas as usinas cumprem essa cláusula. Em caso de não ser possível colher ou negociar a cana com outra indústria, a usina tem indenizado ao fornecedor o valor da produção da "cana bisada", com base em determinada produtividade média negociada entre as partes.

Os fornecedores de cana-de-açúcar de Quirinópolis ainda estão executando o primeiro ciclo de produção da lavoura 
canavieira, alguns com duas e outros com três safras colhidas. $\mathrm{O}$ valor alcançado pela tonelada de cana ficou abaixo dos projetos iniciais, visto que, na época da instalação das agroindústrias e celebração dos contratos de fornecimento de matéria-prima, os preços do açúcar nos mercados internos e externos encontravam-se elevados, fator que é decisivo no cálculo do pagamento da cana-de-açúcar. Mesmo cientes das dificuldades e riscos pertinentes à lavoura canavieira, os fornecedores ressaltam que são menores do que os das demais culturas e também da atividade pecuária, proporcionando uma rentabilidade bem maior. Consequentemente, no vencimento dos contratos, a grande maioria pretende continuar na atividade canavieira.

\section{Assimetrias de poder existentes entre os produtores rurais}

Vale notar que, além das assimetrias de poder estabelecidas nas relações contratuais entre agroindústrias e produtores rurais, existem as assimetrias entre os próprios produtores rurais. Esses agentes não configuram um grupo social homogêneo, uma vez que existem diferenças consideráveis em termos de apropriação dos meios de produção, do capital social e do nível de participação nas instituições de representação de interesses. Isso significa que os agentes sociais adotam ações sociais diferenciadas acerca dos contratos agrários firmados com as agroindústrias. Algumas condições são decisivas para proporcionar algumas vantagens ou desvantagens para os fornecedores de cana.

A área total do imóvel implica assimetrias. Quanto maior a extensão das propriedades maiores serão as chances de as agroindústrias alcançarem seus objetivos expansionistas da cultura canavieira. Na maioria das vezes, as empresas mostram-se mais favoráveis na oferta de vantagens para concretização dos contratos de fornecimento de cana. Os proprietários que dispõem de maior quantidade de terras têm maior poder de barganha e outros benefícios que julgarem interessantes para seus negócios, como menores prazos do contrato - apenas um ciclo.

A localização geográfica dos imóveis também é um fator que pode contribuir ou dificultar o poder de negociação com as agroindústrias. Os imóveis situados próximos às unidades industriais são de grande interesse para a concretização das estratégias das usinas, pois quanto maior a quantidade de área contratada nas suas redondezas maior é a possibilidade de garantia da produção de matéria-prima.

No caso dos fornecedores de cana, a proximidade territorial da agroindústria canavieira implica a percepção de valor financeiro bem maior recebido pelo pagamento da cana, em face dos menores custos despendidos com o transporte da cana. O depoimento de um fornecedor de cana, localizado a quatro quilômetros da usina, é esclarecedor: "Estou muito satisfeito, o valor pago pelo frete é baixo. Meus gastos com irrigação também são baixos, pois uso o vinhoto que eu ganho da usina. Como estou perto, a usina utiliza motor elétrico para bombear a vinhaça para minha lavoura".

A estratégia das agroindústrias para firmar contratos com fornecedores de cana que têm imóveis próximos de suas unidades de beneficiamento fundamenta-se no fato de que, dos poucos proprietários que não concordam em realizar contratos, no início, grande parte deles negociará suas áreas nas safras seguintes. A grande movimentação de máquinas e caminhões, para colheita de cana, causa transtornos para o normal funcionamento da propriedade. Dessa forma, sentindo-se praticamente isolados e cercados pela força do capital representado pela plantação de cana, o que dificulta a manutenção das suas atividades, os agricultores passam a negociar com as usinas, para integrarem-se como fornecedores de cana.

O nível cultural dos produtores rurais também é um fator determinante para diferença de receitas nas negociações. O agricultor com maior nível de conhecimento procura manter-se atualizado, mediante noticiários televisivos e jornalísticos, participação em eventos, seminários e workshop promovidos pelas entidades representativas - Federação da Agricultura do Estado de Goiás, Confederação da Agricultura e Pecuária do Brasil, Serviço Nacional de Aprendizagem Rural - da classe produtora. Logo, por ocasião das negociações com as agroindústrias, eles dispõem de maior quantidade de informações para discutir e reivindicar melhores condições e benefícios 
para aumentar sua renda. Isso não significa, necessariamente, o atendimento dos pleitos por melhores preços de remuneração da cana, mas maior disponibilidade para atuar em defesa de seus interesses econômicos e sociais.

O envolvimento direto dos produtores com as entidades de classe ou sindicatos facilita o diálogo com os diretores das agroindústrias. Deve-se considerar que as agroindústrias canavieiras têm interesse em manter bom relacionamento com os representantes das entidades, que muitas vezes ajudam a convencer produtores indecisos de aderir à produção canavieira. Por conseguinte, os agricultores afiliados e atuantes nas entidades de representação política encontram maior facilidade para atendimento de seus interesses e, desse modo, conseguem aumentar seus rendimentos. Em contrapartida, os produtores que não participam diretamente das entidades classistas enfrentam mais dificuldades para dialogar com os administradores das agroindústrias, o que resulta na menor probabilidade de obter benefícios nas negociações contratuais.

Outros produtores rurais que desfrutam de certas regalias por parte das agroindústrias canavieira, na celebração dos contratos, são aqueles vinculados por laços familiares com agentes sociais que ocupam cargos nas entidades representativas dos agricultores ou que exercem mandatos eletivos, sejam nos níveis federal, estadual ou municipal. As agroindústrias procuram manter boas relações com esses agentes sociais, pois são percebidos como fundamentais nas mediações das negociações com os demais produtores ou com os diversos órgãos municipais, estaduais e federais, para solução de alguma reivindicação das empresas.

Os agentes sociais, afiliados às entidades de representação política ou formadores de opinião, são considerados estratégicos para as relações contratuais das agroindústrias. Estas utilizam-se das negociações efetuadas com os agentes sociais - que são considerados líderes e conhecedores de bons negócios -, para tentar convencer os produtores ainda indecisos a aderir à atividade canavieira. Além de conseguirem novos negócios, os valores pagos, às vezes, ficam aquém do valor de mercado.

A situação econômica e financeira é decisiva para a participação na atividade canavieira. Os elevados custos de formação e manutenção da lavoura canavieira são os principais óbices para os produtores interessados em se tornar fornecedor de cana. Nessa situação poderiam ser incluídos os agricultores com menor quantidade de terra e tecnologia - denominados, pelas atuais políticas de desenvolvimento rural, "agricultores familiares". Por não deterem recursos produtivos, financeiros e conhecimentos tecnológicos de maneira satisfatória, os "agricultores familiares" ficam alijados dos contratos de integração, principalmente como fornecedores de cana.

Já os proprietários de terra com maior poder aquisitivo e que estejam interessados em se tornar fornecedor de cana-de-açúcar encontram maior facilidade para firmar uma relação contratual. Com base nos dados cadastrais, as agroindústrias proporcionam apoio financeiro e tecnológico, além de assistência técnica, isto é, concessão de crédito rural, insumos agrícolas e mudas de cana para formação e manutenção dos canaviais.

Outro tipo de assimetria que faz a diferença entre os agricultores envolvidos na atividade canavieira está relacionado com a autonomia produtiva, derivada do domínio tecnológico, expresso nas máquinas, nos implementos, nos insumos e no conhecimento para fazer os cultivos da cana. Alguns proprietários de terras recebem incentivos das agroindústrias para se tornarem fornecedores de cana-de-açúcar. Porém grande parte dos agricultores que possuem pouca terra e baixo poder de investimento para formação dos canaviais é preterida como fornecedores de cana para fornecimento para usinas, apesar de seu interesse em continuar com as lides rurais.

É patente a existência de assimetrias de poder quando se trata de produtores rurais com conhecimentos agronômicos, como técnicos agrícolas, agrônomos, sócios de empresas de assistência técnica, ou mesmo agricultores com recursos financeiros e tecnológicos, e tradição no cultivo da cana. Esses agentes sociais são considerados fundamentais para auxiliar as agroindústrias na divulgação e formação de opinião a respeito da cultura canavieira, o que contribui para a adesão aos processos de integração de maior número de produtores de cana-de-açúcar. Dessa forma, eles encontram facilidade para obter 
incentivos para produção de cana, posto que as agroindústrias costumam dispensar-lhes os apoios financeiro, tecnológico e mercadológico. Há casos em que as agroindústrias cedem área de terra para plantio de cana, por meio de contratos de subarrendamentos de terras, aos interessados em cultivar cana para fornecimento das unidades industriais, desde que os agentes sociais tenham tecnologias e conhecimento comprovado no cultivo da lavoura canavieira.

\section{Considerações Finais}

Como a maioria das agroindústrias em território goiano não possui terras próprias para cultivo de cana-de-açúcar, o atendimento à sua grande demanda por matéria-prima viria por meio da integração com os produtores rurais, na forma de contratos de fornecimento de matéria-prima. Esses contratos são elaborados pelas agroindústrias canavieiras, que detêm um aparato de informações sobre as leis e instruções normativas que nem sempre são do conhecimento dos produtores rurais. As relações contratuais estabelecidas entre os agentes sociais vinculados ao complexo agroindustrial canavieiro evidenciam um poder assimétrico, uma vez que as agroindústrias canavieiras dispõem de mais informações que os produtores rurais integrados. As diferenças de informação nas transações contratuais alimentam o oportunismo das agroindústrias, denotando que a relação informacional é assimétrica, o que é utilizado para a obtenção de vantagens sobre os produtores. Em que pese ao fato de os contratos serem elaborados com a observância das leis e normas regulamentares pertinentes aos contratos agrários, nota-se que elas são insuficientes para garantir os plenos direitos dos agricultores rurais, em virtude do descumprimento de cláusulas contratuais pelas agroindústrias.

As relações sociais entre os agentes sociais envolvidos - as agroindústrias e os produtores rurais - são, portanto, marcadas por dissensos e conflitos, decorrentes, principalmente, do não cumprimento de algumas cláusulas contratuais por parte das agroindústrias. Apesar desses agravantes, os fornecedores de cana, por vários motivos, mesmo não satisfeitos, aceitam a decisão das agroindústrias, já que precisam manter e continuar seus negócios, por falta de alternativa mais favorável.

Dessa forma, nas negociações para formalizar a integração com os produtores rurais, as agroindústrias, utilizando-se do poder de domínio e de informações, adotam o discurso de que os agentes sociais dessa relação são "parceiros", no sentido de que estão imbuídos do objetivo comum de desenvolver a atividade canavieira. Com isso, os produtores, interessados em concretizar a negociação, assumem o discurso da usina e se consideram como "parceiros".

Apesar da existência de impasses e conflitos, os fornecedores de cana goianos submetem-se às condições impostas pela agroindústria e dificilmente rescindem seus contratos ou abandonam a atividade canavieira. Afinal, com outras culturas como soja, milho, feijão e arroz, ainda que os custos de sua produção sejam inferiores, os riscos são invariavelmente maiores e os lucros menores.

Outrossim, as assimetrias de poder existentes entre as partes contratantes, quando são elaborados os contratos, são fatores determinantes para a confecção de contratos incompletos. Com isso, as agroindústrias canavieiras detêm grande força de poder e barganha diante dos proprietários de imóveis e fornecedores de cana-de-açúcar. Cônscios de que estão em desvantagens nos negócios, os agricultores sentem-se o lado mais fraco, com carência de informações para discutir ou exigir o cumprimento de cláusulas contratuais descumpridas pelas agroindústrias. Mesmo discordando e ressentidos, eles sentem-se obrigados a se sujeitar às imposições estabelecidas, em prol da continuidade do negócio.

Os fornecedores de cana-de-açúcar não configuram um grupo social homogêneo, pois existem diferenças consideráveis em termos de apropriação dos meios de produção, do capital social e do nível de participação nas instituições de representação de interesses, que favorecem a adoção de ações sociais diferenciadas acerca dos contratos agrários firmados com as agroindústrias. Essas diferenças socioeconômicas são decisivas para proporcionar algumas vantagens ou desvantagens para cada classe de fornecedores de cana. 
O poder das agroindústrias que emerge das assimetrias de poder reduz o alcance das ações sociais dos produtores rurais e suas poucas entidades de representação. As informações existentes entre as partes contratantes facilitam o oportunismo das agroindústrias canavieiras na elaboração dos contratos, com a prestação de informações imprecisas, incompletas ou incorretas, o que é determinante para gerar prejuízos financeiros e econômicos aos agentes sociais, quais sejam os fornecedores de cana.

\section{Referências}

BRASIL. Lei $n$. 4.504, de 30 de novembro 1964. Dispõe sobre o Estatuto da Terra, e dá outras providências. Disponível em: <http://legislacao.planalto.gov.br/ legisla/legislacao> Acesso em: 10 jan. 2009.

FIANI, R. Teoria dos custos de transação. In: KUPFER, D. K.; HASENCLEVER, L. (Org.). Economia industrial: fundamentos teóricos e práticos no Brasil. 1. ed. Rio de Janeiro: Campus, 2002. p. 267-286.
PAULILO, M. I. S. Produtor e agroindústria: consensos e dissensos: o caso de Santa Catarina. Florianópolis: Ed. UFSC, 1990.

PAULILLO, L. F.; ALMEIDA, L. M. A coordenação agroindustrial citrícola brasileira e os novos recursos de poder: dos políticos aos jurídicos. Organizações rurais e agroindustriais, Lavras: UFLA, v. 11, p. 11-27, 2009.

SEPLAN - Secretaria do Planejamento e Desenvolvimento - Superintendência de Estatística, Pesquisa e Informações. Estatísticas municipais: séries históricas. Goiânia: Seplan, 2010. Disponível em: <http://www. seplan.go.gov.br/>. Acesso em: 10 mar. 2010.

VIAN, C. E. F. Agroindústria canavieira estratégias competitivas e modernização: Campinas, SP: Átomo, 2003.

WAACK, R. S.; NEVES, M. F.; MORAES, S.; MARINO, M. K.; MAMONE, A.; SZASZ, A. H. Sistema agroindustrial da cana-de-açúcar/Sistema agroindustrial da soja. In: FARINA, E. M. E. Q.; ZYLBERSZTAJN, D. (Coord.). Competitividade no agribusiness brasileiro. São Paulo: PENSA/FIA/FEA/USP, 1998; Programa de Estudos dos Negócios do Sistema Agroindustrial (PENSA)/ Fundação Instituto de Administração (FIA)/Faculdade de Economia, Administração e Contabilidade (FEA). 194p. Disponível em: <http://www.fea.usp.br/fia/ pensa/pdf/acucar.pdf $>$. 